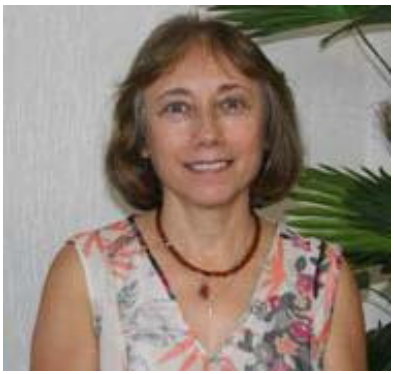

\title{
A DISSEMINAÇÃo DO CONHECIMENTO CIENTÍFICO: DESAFIOS E PERSPECTIVAS
}

\section{Margarita Antonia Villar Luis}

A divulgação do trabalho constitui, na atualidade, o grande desafio de pesquisadores e de todos aqueles profissionais que se propõem a compartilhar suas experiências entre os seus pares. Afinal, o objetivo de quem desenvolve um projeto criativo, inovador ou não, realiza uma síntese analítica de um conjunto de conhecimentos, ou descreve e discute um relato de experiência, e isso é, também, apresentar a sua obra à comunidade acadêmica, aos profissionais interessados pelo seu tema e a grupos da população como um todo, visando ampliar o conhecimento, instigar outros para a pesquisa de um tópico específico e, inclusive, submeter os seus achados ao crivo de outros expertos no tema.

Cada vez mais se observa que publicar o trabalho não é o suficiente, publicar e ser citado em revistas de impacto se tornou necessidade, no entanto, quem só divulga o seu material na língua portuguesa não consegue ser lido, muito menos citado. Claro que a língua pode ser uma barreira importante, mas não é a única, se assim fosse uma boa assessoria para tradução solucionaria o problema. A questão vai mais além, faltam conhecimento e treinamento dos autores no tocante à compreensão do que seja um artigo científico e do tipo de formato para publicação em revistas de nível internacional. Outro aspecto diz respeito ao conteúdo do artigo, sendo que, por vezes, se observa a falta de domínio da linguagem científica ou, até mesmo, da criatividade para desenvolver contribuições originais, limitando-se a reproduzir conhecimento já divulgado(1).

O não domínio do inglês, considerado o idioma da ciência, tem dificultado a aceitação de artigos de pesquisadores de países emergentes por revistas internacionais estrangeiras, sob a alegação de que necessitam de revisão linguística, quando não são rejeitados na primeira investida. Assim, o pesquisador sem suporte institucional, para a produção de ciência escrita nesse idioma, tem sua capacidade de trabalho limitada, pois terá dificuldade para estabelecer parcerias com colegas de centros de excelência em pesquisa, situados em países de língua inglesa.

Cabe a ressalva de que, em algumas áreas do conhecimento, dadas as suas características, o interesse ainda permanece centrado em questões de âmbito local, favorecendo o idioma do país, o português e o espanhol, particularmente na América Latina.

Quando a relevância da pesquisa centra-se em problemas de natureza local, geralmente isso ocorre devido ao fato de seu objetivo visar resultados, cujo impacto esperado é alcançar populações ou comunidades específicas, auxiliando, por exemplo, no desenvolvimento ou implementação de políticas públicas.

Em que pese o conhecimento globalizado, a ênfase na divulgação ampliada do conhecimento científico, favorecendo a investigação em temas de relevância internacional, o foco em questões de interesse regional ou local, não desmerece o valor de uma pesquisa. A leitura de um texto de escrita agradável, reflexiva, que favoreça a internalização do conteúdo expresso, estimulando mudanças de atitudes e práticas profissionais, para, na sequência, resultar em mudança de conhecimento puro, constitui-se em um tipo de impacto também necessário ${ }^{(2)}$.

Para alguns públicos específicos, as experiências localizadas podem ser inspiradoras para o desenvolvimento de pesquisas em seus espaços de atuação, ou, ainda, despertar aspectos não considerados em investigações já realizadas. Resultados de trabalhos científicos localizados podem gerar motivações para iniciar ou ampliar a comunicação científica entre pesquisadores e para replicar e aprofundar conhecimento obtido localmente.

É bem verdade que a escolha de publicar em revistas científicas regionais ou internacionais tem consequências para a pesquisa publicada, pois a direção em favor da segunda opção confere maior visibilidade, principalmente se a revista for de alto impacto ${ }^{(3)}$.

Cabe ao autor do trabalho ponderar com sabedoria, pois, não poucas vezes, mandará o seu trabalho para revistas de maior impacto e, entre envios e devoluções, podem decorrer de poucos meses até um ano, correndo o risco de, a depender da natureza do artigo, o seu conteúdo perder a atualidade e seu aspecto original. Ressalte-se que, dependendo da área, as revistas com alta cotação científica sempre têm muita oferta de pesquisas e podem ser extremamente seletivas. 
A aspiração de editores de revistas científicas centra-se em publicar artigos julgados de boa qualidade científica, que agreguem conhecimento a seus leitores e, ainda, em melhorar o impacto da sua revista entre a comunidade científica, de forma a diminuir o caráter regional, situando-a num melhor nível acadêmico, para competir com outras internacionais publicadas no país e no exterior.

A carência de revistas nacionais capazes de mostrar a qualidade da ciência de um País é um impeditivo da sua autonomia científica. Os bons pesquisadores são impelidos a publicar em revistas do exterior e, com isso, enfrentam a concorrência acirrada com outros pesquisadores dos respectivos países, bem como a proteção por parte dos editores estrangeiros, para com os seus cientistas ${ }^{(4)}$.

Apesar de todo jornal científico servir ao leitor mediante o compromisso de publicar os avanços mais interessantes da ciência, desde o final do século XX, tem aumentado a tendência de editores dos países, ditos desenvolvidos, visualizarem as publicações acadêmicas como meio de gerar lucro e, com isso, os artigos melhores e mais interessantes têm servido aos interesses comerciais dos publicadores, que querem leitores para comprar os artigos publicados em suas revistas ${ }^{(3)}$.

Nesse cenário, nem um pouco neutro, as revistas científicas nacionais assim como os pesquisadores enfrentam muitos obstáculos, as primeiras lutam pela busca de recursos de toda a sorte para sobreviverem (financeiros, pessoal técnico capacitado, revisores disponíveis e experientes, artigos científicos originais), da mesma forma os segundos se veem envolvidos numa trama similar, pois sua sobrevivência acadêmica depende de recursos (também financeiros e técnicos) para o desenvolvimento da pesquisa e da publicação dos resultados, com exigências crescentes nesse quesito.

Para sobreviver, a revista nacional necessita se tornar atrativa a outros leitores, mesmo contando com a garantia de um grupo mais interessado em questões locais, deve buscar expandir seus horizontes, visando outros continentes, a despeito do desafio que isso pressupõe.

Pontos essenciais, para alcançar o nível de internacionalização, se referem aos procedimentos de avaliação que precisam ser elevados, atingindo padrões internacionais, profissionalização de operações, garantindo a presença de cientistas internacionais, com experiência editorial, para se juntar ao grupo central de editores-chefes. As habilidades desses últimos no idioma inglês, a experiência em área específica de pesquisa, assim como sua influência na comunidade acadêmica, induziria a melhoras na visibilidade do jornal e na sua qualidade ${ }^{(3)}$.

Outro aspecto importante diz respeito às estruturas editoriais, que não podem se limitar a pesquisadores locais e, principalmente, de uma única instituição. A responsabilidade deve ser compartilhada com outros pares, pois cabe a seus componentes o estabelecimento das diretrizes e padrões da pesquisa científica a ser publicada, bem como os critérios que nortearão o julgamento dessa pesquisa pelos revisores. A presença de cientistas de outros países em que a produção científica, do espectro temático da revista, é de qualidade reconhecida internacionalmente constitui passo decisivo rumo à meta de aproximação da mesma ao tão almejado nível internacional ${ }^{(3)}$.

Certamente que a publicação na língua inglesa auxilia na disseminação do conhecimento, apesar da qualidade das traduções deixar muito a desejar, mas, de qualquer forma, bons artigos sempre são mais compreensíveis e, nessa direção, a SMAD publica os dois últimos números também em inglês. Trata-se de um esforço para promover a revista em âmbito internacional. Por esse fato, os custos não foram repassados aos autores, no futuro talvez precisemos socializar os gastos.

Haverá novas mudanças, necessárias para atingir propósitos mais ambiciosos em termos de qualidade científica, criatividade e inovação. Queremos a participação de nossos leitores e sua contribuição pode ser efetiva, sugerindo nome de cientistas reconhecidos, nos temas de saúde mental e álcool e outras substâncias psicoativas, para que componham o nosso quadro de revisores.

\section{Referencias}

1. Marques F. A barreira do idioma. Pesqui FAPESP. ago 2009;(162):39-41.

2. Porta M, Copete JL, Fernandes E, Alguacil J, Mutillo J. Mixing journal, article, and author citations, and other pitfalls in the bibliographic impact factor. Cad Saúde Pública. 2003;19(6):1847-62.

3. Meneghini R. Emerging journals. EMBO Reports (Print). 2012;13(2):106-8.

4. Rocha e Silva M. O segredo da visibilidade. Pesqui FAPESP. jan 2012;(191):28- 33.

Margarita Antonia Villar Luis

Editora da SMAD, Revista Eletrônica Saúde Mental Álcool e Drogas e Professor Titular da Escola de Enfermagem de Ribeirão Preto, Universidade de São Paulo, Centro Colaborador da OMS para o desenvolvimento da pesquisa em enfermagem, Brasil, e-mail: margarit@eerp.usp.br

\section{Como citar este artigo:}

Luis MAV. A disseminação do conhecimento científico: desafios e perspectivas. SMAD, Rev. Eletrônica Saúde Mental Álcool Drog. (Ed. port.). maio-ago. 2011 [acesso: ];7(2):53-4. Disponível em:

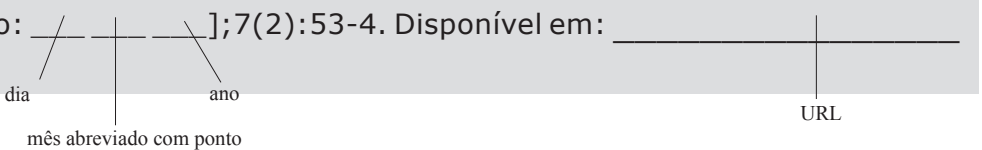

